\title{
Evaluating the costs of pneumococcal disease in selected Latin American countries
}

\author{
Dagna Constenla ${ }^{1}$
}

Suggested citation Constenla D. Evaluating the costs of pneumococcal disease in selected Latin American countries. Rev Panam Salud Publica. 2007;22(4):268-78.

ABSTRACT Objectives. To estimate the costs of pneumococcal disease in Brazil, Chile and Uruguay, to describe how these costs vary between different patient groups, and to discuss factors that affect these cost variations.

Methods. The cost of pneumococcal disease was estimated from the health care perspective. For each country, baseline cost estimates were primarily developed using health resources information from patient-level data and facility-specific cost data. A regression model was constructed separately for four types of pneumococcal diseases. The skewness-kurtosis test and the Cook-Weisberg test were performed to test the normality of the residuals and the heteroscedasticity, respectively.

Results. The treatment of pneumococcal meningitis generated up to US\$ 5435 per child. The treatment costs of pneumococcal pneumonia were lower, ranging from US\$ 372 per child to US\$ 3483 per child. Treatment of acute otitis media cost between US\$20 per child and US\$ 217 per child. The main source of treatment costs variations was level of service provided and country in which costs were incurred. However, the tendency of costs to change with these variables was not statistically significant at the 5\% level for most pneumococcal disease models. Conclusions. Pneumococcal disease resulted in significant economic burden to selected health care systems in Latin America. The patterns of treatment cost of pneumococcal disease showed a great deal of variation.

Key words Costs and cost analysis, cost of illness, otitis media, pneumonia, pneumococcal meningitis, regression analysis, Streptococcus pneumonia, Latin America.

Streptococcus pneumoniae, or pneumococcus, causes a number of clinical conditions, such aspneumonia, meningitis, bacteremia, sepsis, and acute otitis media (AOM). Pneumococcus is

\footnotetext{
${ }^{1}$ Health Service Research Unit, Department of Public Health \& Policy, School of Hygiene and Tropical Medicine, London, England. Send correspondence to: Dagna Constenla, 1000 W. Horsetooth Road, F2, Fort Collins, Colorado, 80526, U.S.A. telephone/fax: (970) 266-1153; e-mail: dagnaconstenla@yahoo.com
}

considered to be one of the main pathogens in infants under 3 months old and the most important cause of meningitis in that age group (1). An estimated 1.6 million deaths are due to pneumococcus each year. The majority are caused by pneumococcal pneumonia, of which approximately 800000 are among children less than five years of age (2). While the primary impact of pneumococcal infection is on child health, the infection also creates an economic burden on affected individuals, their families, and society as a whole.

In spite of the extensive impact of the disease, only limited data are available on the current economic burden imposed by pneumococcal disease (3-15). Over half of these studies come from North America and Europe (3-6, 9-11), while only a handful of these studies come from Latin American countries $(7-8,12-15)$. It is not clear 
from these studies which forms of treatment associated with pneumococcal disease are costed, which are included in the total cost estimates, and how these estimates are made. Cost data derived from some of these studies are generally poor, not applicable to other populations, and not representative of the true economic costs of pneumococcal disease. Moreover, none of these studies identified the source of variations in treatment costs. This is an important consideration in cost-effectiveness studies because costs can vary widely by country and practice patterns. Cost-effectiveness studies are useful particularly for policy makers who must make rational decisions about the efficient allocation of resources. But for results to be used in this process, they need to be comparable across alternative uses of money. The present study provides a unique opportunity to explore variation in treatment costs of pneumococcal disease across distinct settings in Latin America.

The goal of this study was to provide decision makers with estimates of the costs of pneumococcal disease in Brazil, Chile, and Uruguay, as well as to examine the various ways in which cost data can vary and the factors that can affect these variations. This study was conducted as a companion analysis to a cost-effectiveness analysis of the pneumococcal conjugate vaccine conducted in the same countries. The methods and results of the costeffectiveness analysis have been described in detail elsewhere (16).

\section{MATERIALS AND METHODS}

We estimated the cost of treating four illnesses in selected countries: acute otitis media (AOM) due to any cause, pneumonia due to any cause, pneumococcal pneumonia, and pneumococcal meningitis. These costs were calculated by combining estimates of the number of each type of event (hospital and ambulatory) with information on the costs associated with the event. We chose to analyze AOM due to any cause and pneumonia due to any cause, rather than pneumococcal AOM or pneumococcal pneumonia, because it was not possible to confirm the presence of pneumococcus in children with AOM or pneumonia treated in ambulatory settings.

For hospital and ambulatory events, the costs were partitioned into the cost of the visit (including facilities and personnel) and the cost of the resources used for treatment (specific tests, procedures, and medications). All cost estimates were collected in local currency and were converted to 2004 U.S. dollars using the official exchange rates derived from the World Development Indicators (17).

Two analyses were conducted. In the base case analysis, cost-generating events were estimated based on a prospective multi-center observational study (16) that followed patients from January and September 2001 in the ambulatory and hospital settings. The objective of this observational study was to estimate the treatment costs of pneumococcal disease in Brazil, Chile, and Uruguay. These countries were selected on the basis of their availability of health economic data and their willingness and ability to participate. The country's economic, social, and political climate was also a consideration although it was not a necessary condition for inclusion. We considered the health care system perspective, in which only the costs borne by medical facilities were considered.

In the secondary analysis, we used the data from the same multi-center observational study to describe the patterns of child-level costs associated with pneumococcal disease, and determine the source of variations across countries on the total treatment costs of pneumococcal disease. The perspective of this analysis was also the health care system.

\section{Multi-center observational study}

The multi-center observational study was conducted in several sites (33 hospitals and 10 ambulatory centers) across the selected countries. These sites were generally made up of sec- ondary or tertiary-level facilities. The facilities were purposely selected to ensure comparability in terms of number of beds, range of facilities, catchment population, and geographic coverage. The choice of facilities at the various referral levels was also an attempt to obtain a broad case mix. When selecting hospitals or clinics within each country, certain conditions within that country were considered. These included variations in clinical practice and how representative they were. Another important consideration was access to hospital information and completeness of medical records.

For ambulatory care centers, the judgment of whether a health care center was "representative" was left to the discretion of the local investigators. The selection of health centers was random within the catchment area of the hospitals being studied, depending on the number of children presenting with pneumonia due to any cause and AOM due to any cause, and the willingness of health care authorities to participate. Each local investigator undertook this formally with the appropriate authorities in the centers that could authorize access.

Ninety percent of the data collected in the hospitals was retrospective. A subset of $10 \%$ newly and consecutively admitted children fulfilling the inclusion criteria was subjected to prospective data recording. Their data were compared to those retrospectively collected to determine whether differences in the recording of health resources existed. If there were no gross differences, their data were summarized with a total $n$ equal or less than 100 or 200 (90 or 180 retrospectively collected and 10 or 20 prospectively collected). If there were differences, the utilization rates were examined to determine where the differences could be attributed. Adjustments were made depending on the reason for those differences. Alternatively, the two estimates were presented separately. All the health resources information collected in the ambulatory centers was prospective.

Various questionnaire surveys were piloted and used to collect health care 
utilization and unit cost data on children seeking medical attention for pneumococcal illnesses. These have been described in detail elsewhere (16). Survey data were analyzed using Microsoft ${ }^{\circledR}$ Office Access 2003 statistical software. Separate estimates were generated for hospitalized children (pneumococcal pneumonia, pneumococcal meningitis) and ambulatory children (AOM due to any cause and pneumonia due to any cause). Ambulatory children were defined as those who spent less than one day in the hospital. Hospitalized children were children who stayed more than one day in the hospital. Health resources information was collected for eight months. Complete data were available for 753 children (371 hospitalized children and 382 ambulatory children) under five years of age with confirmed pneumococcal disease (pneumonia and meningitis), pneumonia due to any cause, and AOM due to any cause.

\section{Sample size}

A total of 753 children were included in the study (166 children from Brazil, 400 from Chile and 187 children from Uruguay). The sample size for this study varied by country depending on the country's population, the number of children presenting with pneumococcal disease, and the level of access to urban/rural facilities. Conversely, the sample size varied by hospital depending on the size of the hospital (number of beds did not exceed 300 for tertiary care), occupancy rate (approximately 80\%-85\%), and qualityof-care (e.g., the net death rate was less than $2 \%$ or less than $2 \%$ deaths among those hospitalized for more than 48 hours).

Using discharge diagnoses for children who had been admitted to hospital over a two-year period (maximum of three years) and discharge logbooks (for ambulatory centers), a list of 753 children was prepared. This list contained the child's chart number, child's age, and date of admission. This information was obtained for each eligible child in order to generate four sampling frames: one for pneumococcal pneumonia, the second for pneumococcal meningitis, the third for pneumonia due to any cause, and the fourth for AOM due to any cause. These were sorted according to date of admission to the hospital or date of attendance at the ambulatory center. A form was provided for keeping track of the sampling frame. Individual charts were then gathered and abstracted beginning with the most recent cases and working in reverse chronological order until there were approximately 50 cases per country (Brazil and Uruguay), and 100 cases in Chile. The sample size for Chile was doubled because the study covered a wider geographic area (three main cities in Chile instead of one, as was the case for Brazil and Uruguay).

A systematic sampling of children was performed to avoid any potential seasonal biases. Replacement was done if the child initially selected did not fulfill any of the inclusion criteria or was lost to follow-up. The next child in the list was selected until the required sample size $(n<50$ or 100 per disease) was obtained.

\section{Use of health resources}

Information on the use of health resources for the treatment of pneumococcal pneumonia, pneumococcal meningitis, AOM due to any cause, and pneumonia due to any cause was collected about the 753 children based on standard (observed) practice and included what was done for the child. Hospital and ambulatory services included hospital bed days, visits to ambulatory clinics, hospital and outpatient care, and community care services (general practice visits, nurse visits, ambulance). Categories of each type of service specific to each country were developed and were based on information derived from hospitals and ambulatory centers in each country. Direct recurrent inputs captured included nursing time, doctor's time, laboratory tests, use of radiography, hotel services (bedding and food), drugs, and other medical supplies. We established health resources profiles for each case to learn patterns of disease and assist in the identification of the level of each resource input. Health resources profiles per case included: acute care versus critical care versus continuing care; hospital care versus ambulatory care; mild versus severe cases; and acute versus chronic cases.

\section{Cost estimates}

The average cost of treatment per child was estimated using the health resources data obtained from the survey questionnaires used in the multicenter observational study. These data were combined with unit costs of each health resource item from various hospital finance departments. A stepdown costing method was employed here to measure average costs. We developed categories of costs specific to each country. This approach offered the advantage of using empirical methods to reflect country-specific costs.

We estimated the costs for pneumonia due to any cause and pneumococcal pneumonia separately because the management of these two diseases differed considerably. Direct nonmedical costs and indirect costs were not reported here to allow for consistency in reporting the two analyses. These costs are described in detail elsewhere (16).

Health care costs were calculated as the sum of the visit cost at the hospital or outpatient setting, the cost of diagnostics, and the cost of medication. For Brazil, the hospital per diem cost was an average estimate based on the Unified Health System (UHS), taken from the actual hospital per diem cost of a pediatric infectious disease ward for pneumococcal pneumonia and pneumococcal meningitis. Estimates of the hospital per diem costs in Chile and Uruguay were derived from the finance departments of various hospitals that were representative of each country (16). For all countries, the cost per stay in the hospital was calculated by multiplying the per diem rate of a 
pediatric infectious disease ward (which includes hotel costs, food, and health personnel) by the mean length of stay, which was derived from the multi-center observational study. The cost per ambulatory visit was calculated as the weighted mean cost of visiting a pediatrician, general practitioner, or emergency room based on the proportion seen in each of the ambulatory visits. The unit cost for each diagnostic test and medication was based on estimates provided by the finance departments of public hospitals and from the listing of medications and national formularies, respectively.

\section{Secondary analysis}

We chose four different categories to characterize the patterns of costs associated with pneumococcal disease: age, diagnosis, country, and level of care. The differential cost by age was assessed to determine whether a disproportionate amount of the costs of pneumococcal disease occurred in certain age groups. Children were divided into five different age groups: 0-11 months, 12-23 months, 24-35 months, 36-47 months, and 48-59 months. Each age group was evaluated separately and by type of setting (hospital and ambulatory).

In addition, we developed four different diagnostic categories to find out which condition was the most resource intensive. The diagnostic categories were based on the International Classification of Diseases, 10th Revision Clinical Modification (ICD-10-CM), codes (18). The following diagnoses were considered based on ICD-10-CM codes: pneumonia due to any cause (J15); pneumococcal pneumonia (J13); pneumococcal meningitis (G00.1); and AOM due to any cause (H65.0). Each diagnostic category was evaluated separately in each country.

We also grouped children into six different types of care to describe how costs behave at various levels of care: ambulatory care, domiciliary care (Uruguay only), emergency care, intensive care, intermediate (neonatal) care, and regular care. These repre- sented the most common places where care was provided to children with pneumococcal disease (16).

We performed multiple linear regression analysis using the statistical data analysis software STATA ${ }^{\mathrm{TM}}$ version 5.0 for Windows (StataCorp LP, College Station, Texas, U.S.A.). This analysis was performed to determine the source of cost variations across countries. Health care costs for pneumococcal diseases were modeled separately. We constructed four disease models (model 1: pneumococcal meningitis; model 2: pneumococcal pneumonia; model 3: pneumonia due to any cause; and model 4: AOM due to any cause) to predict how well the dependent variable (cost) was used to predict the independent variables (age, gender, country, and level of care).

The independent variables were as follows: age $\left(x_{1}\right)$, country (Brazil: $x_{2}$, Uruguay: $\left.x_{3}\right)$, gender $\left(x_{4}\right)$, and level of care $\left(x_{5}\right)$. We defined age as children under five years old, and gender as male or female. Chile was chosen as the reference country from which to compare cost variations across countries. Therefore, the independent variable country was either Brazil or Uruguay. The level of care was defined as low-level care (ambulatory care or domiciliary care) or high-level care (emergency care, intensive unit care, or intermediate neonatal care). We compared these independent variables to cost of pneumococcal disease using the Student $t$ test and the chisquare test. These tests were applied to continuous and categorical variables, respectively. The number of observa-

TABLE 1. Distribution of children treated for pneumococcal disease in ambulatory or hospital settings by age groups, Brazil, Chile and Uruguay

\begin{tabular}{|c|c|c|c|c|c|c|c|}
\hline \multirow{2}{*}{$\begin{array}{l}\text { Age group } \\
\text { (months) }\end{array}$} & \multicolumn{2}{|c|}{ Brazil } & \multicolumn{2}{|c|}{ Chile } & \multicolumn{2}{|c|}{ Uruguay } & \multirow[b]{2}{*}{ Total } \\
\hline & Ambulatory & Hospital & Ambulatory & Hospital & Ambulatory & Hospital & \\
\hline $0-11$ & 27 & 40 & 54 & 109 & 39 & 42 & 311 \\
\hline $12-23$ & 13 & 36 & 51 & 45 & 25 & 21 & 191 \\
\hline 24-35 & 17 & 8 & 48 & 11 & 18 & 8 & 110 \\
\hline $36-47$ & 7 & 7 & 38 & 5 & 10 & 11 & 78 \\
\hline $48-59$ & 2 & 8 & 30 & 11 & 5 & 7 & 63 \\
\hline Total & 66 & 99 & 221 & 181 & 97 & 89 & 753 \\
\hline
\end{tabular}

tions for models 1 through 4 was 183, 187,178 , and 205, respectively.

Assuming cost (dependent variable) was not normally distributed, the scale on which the data were analyzed was transformed to obtain a normal distribution. This assumption was based on observations from the multi-center observational study (16). We transformed the dependent variable cost by taking its natural logarithm. The natural logarithm was chosen because it is the most frequently used transformation.

Coefficients that were statistically significant at the $5 \%$ level had $t$ ratios that were either greater than 2 or less than -2 . Residuals were computed to ensure that each equation satisfied the assumptions of normality. We computed the skewness-kurtosis test to check the null hypothesis that the residuals were normally distributed.

Additionally, we tested the assumption of no heteroscedasticity, that is, there was a non-constant variance across the predicted values of $y$, using the Cook-Weisberg test (19). The null hypothesis was of constant variance (i.e., no heteroscedasticity). This meant that the predicted values of $y$ could not be rejected at the $5 \%$ level if the $P$ (chisquare) given was greater than 0.05 .

\section{RESULTS}

\section{Distribution of children with pneumococcal disease by age categories}

Table 1 provides the distribution of children treated for pneumococcal dis- 
ease in ambulatory or hospital settings by age groups. Overall, $41 \%$ of children with pneumococcal disease were under one year old, $25 \%$ were 12 to 23 months old, and $34 \%$ were over two years old. This suggests that the majority of the children with pneumococcal disease belonged to the younger age groups (0-23 months). This was consistent in all three countries.

\section{Cost of treatment across countries}

The breakdown of mean total cost per child for treatment of pneumococcal disease in the public sector across countries is presented in Table 2. Fiftysix percent of the overall treatment cost of pneumococcal disease was attributed to Chile, and the remaining $29 \%$ and $15 \%$ to Uruguay and Brazil, respectively. Across countries, hospitalization was the main component of cost associated with pneumococcal disease, followed by concomitant medications (e.g., paracetamol, decadron, dexamethasone, ranitidine, acyclovir) in Brazil and Chile, and surgery in Uruguay. Hydration and electrolyte therapies were an important cost component in Brazil, as were ambulatory visits in Chile, and other related procedures (e.g., lumbar puncture, tympanoplasty , transfusion, thorascentesis, and catheter insertion) in Uruguay. Across countries, the highest costs reported were attributed to pneumococcal meningitis, which accounted for $58 \%$ of the total cost of pneumococcal disease. AOM due to any cause was by far the cheapest infection to treat, accounting for only $3 \%$ of the total treatment cost of pneumococcal disease.

\section{Use of health resources by age}

Children in the youngest age group (0-11 months) were found to be the most resource intensive (Table 1). We found that $52 \%$ (191 of 369) of hospital admissions were for children less than one year old. In contrast, only onethird (120 of 384) of ambulatory visits were reported for the youngest age group. Approximately 28\% (102 of 369 ) of hospital admissions and 23\% (89 of 384) of ambulatory visits were reported in children 12-23 months old. Less than one-fourth (76 of 369) of hospital admissions were reported in children 24-59 months old, while almost one-half (175 of 384) of ambulatory visits were reported in the older age groups. Hospitalization was a major contributor of the overall treatment cost $(50 \%-61 \%)$ for the younger age groups due to the longer length of stay that is characteristic of this age group.

Cost variations for the different age groups were also observed at the country level. The overall cost of treatment reported in the younger age groups (0-23 months) was higher in Chile (US\$ 939) and Uruguay (US\$ 872) than in Brazil (US\$ 144). This suggests different patterns of treatment across countries. Quite the contrary occurred in the older age groups, where higher costs were reported among older Brazilian children (24-59 months old). This was because more severe cases were reported among older Brazilian children. For children with more disabling conditions (e.g., complications, sequelae), different patterns of treatment were found. Younger children (0-23 months old) with complications or sequelae incurred higher treatment costs than older children (24-59 months old) with the same disabling conditions. This was the case for children living in Chile and Uruguay. Sixty-four percent of the total treatment costs of children in the older age group (48-59 months old) were due to drug therapy (antibiotics and concomitant medications such as paracetamol, decadron, dexamethasone, ranitidine, acyclovir), indicating a greater reliance on drug management in the older age group.

In summary, age had a considerable effect on the cost of treatment. Children in the youngest age groups (0-24 months old) tended to have more severe or disabling conditions. Approximately, 68\% (124 of 183) of children in this age group were reported to have pneumococcal meningitis and experienced complications and/or sequelae because of this disease. This resulted in a greater number of children being hospitalized for their illness with a considerable length of stay in hospital; hence, the higher costs of treatment for this age group.

\section{Use of health resources by type of pneumococcal illness}

Table 3 shows that the use of health resources was directly related to the type of pneumococcal illness in Brazil, Chile, and Uruguay. Children consigned to ICD-10 codes J13 (pneumococcal pneumonia) and G00.1 (pneumococcal meningitis) were treated in the hospital and, as a result, were the most resource intensive. Less disabling conditions (e.g., AOM due to any cause and pneumonia due to any cause) were generally managed in ambulatory settings as was evident by the elevated rate of consultations reported for ICD-10 codes J15 (pneumonia due to any cause) and H65.0 (AOM due to any cause). No surgical interventions or hydration and electrolyte therapies were reported for these diagnostic groups, giving further evidence of the less disabling nature of pneumonia due to any cause and AOM due to any cause.

Eighty-three percent of the cost was attributed to the management of severe disease (pneumococcal meningitis and pneumococcal pneumonia), and the remaining $17 \%$ to less severe conditions (AOM due to any cause and pneumonia due to any cause). Across countries, hospitalization and surgery were the main components of the cost associated with severe disease (pneumococcal meningitis and pneumococcal pneumonia), and drug therapy became the most important element of the treatment of less severe conditions (AOM due to any cause and pneumonia due to any cause).

\section{Use of health resources by level of care}

Table 4 summarizes the use of health resources by level of care for children with pneumococcal illness in Brazil, 


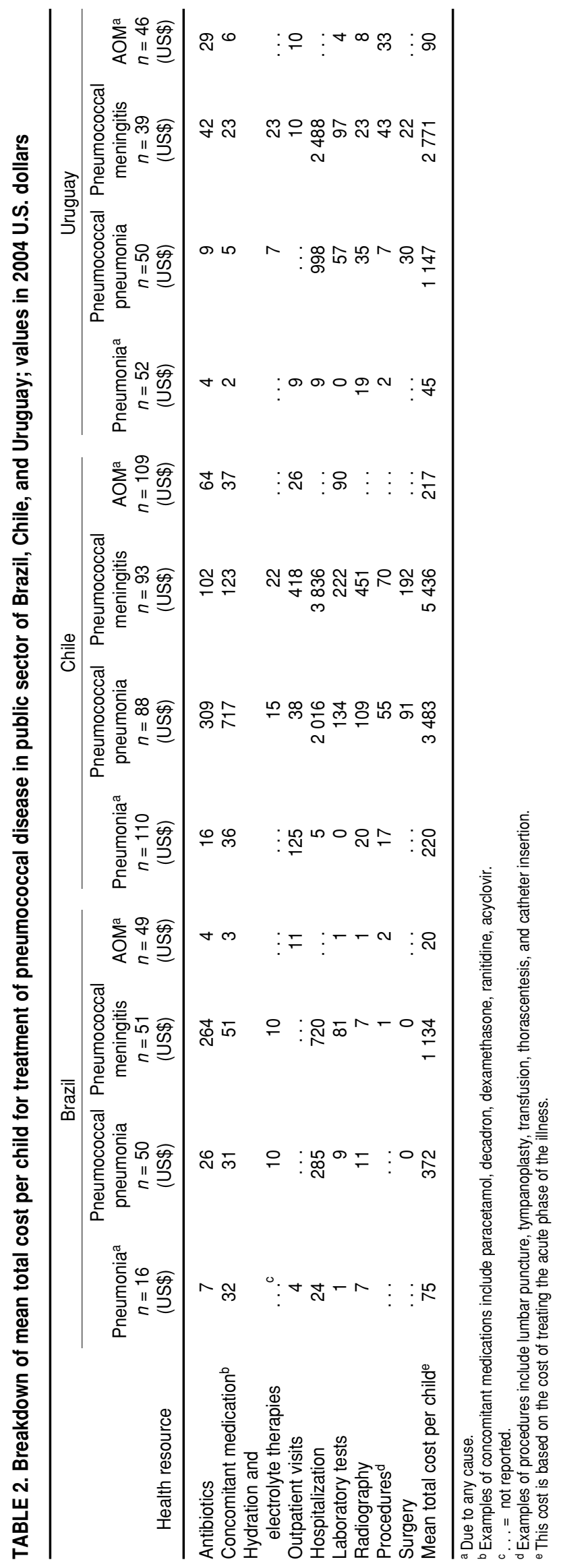

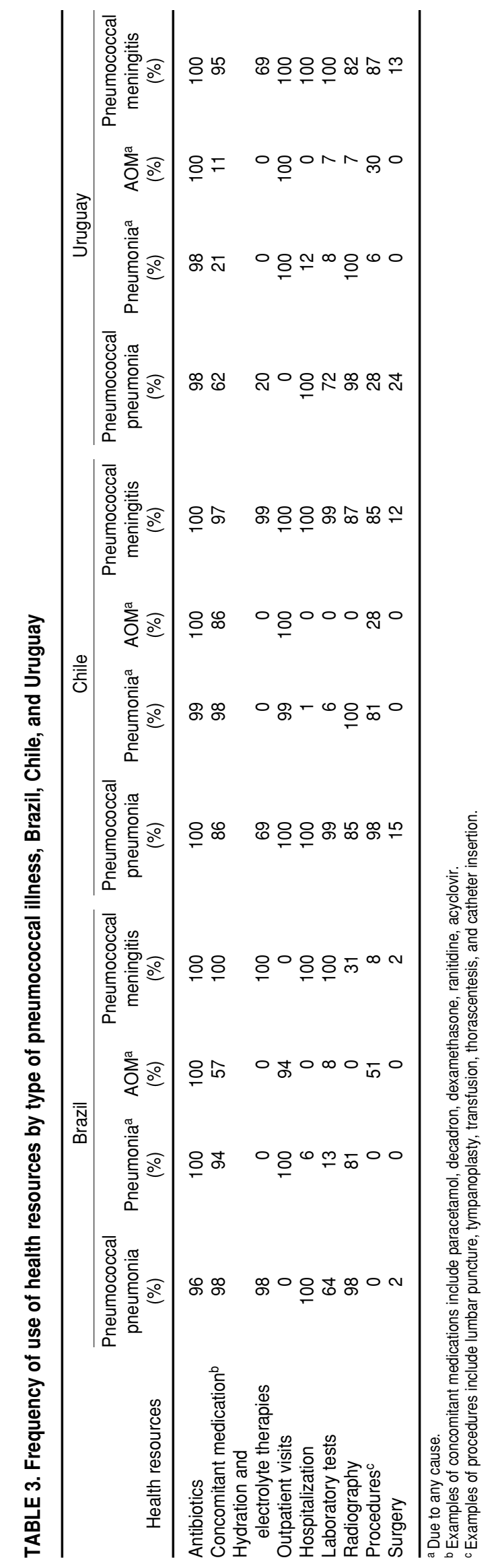


TABLE 4. Use of health resources by level of care for children with pneumococcal illness in Brazil, Chile, and Uruguay

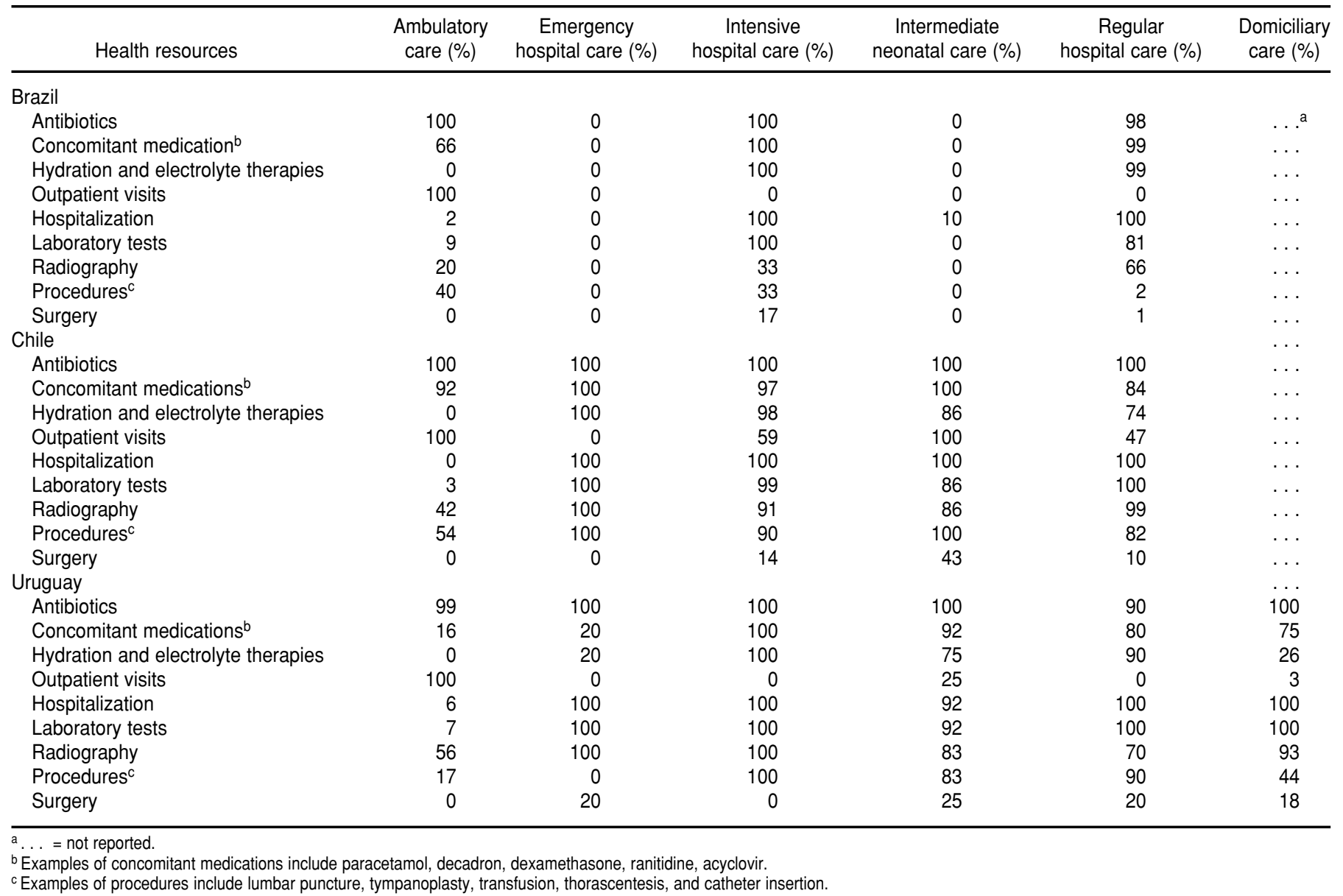

Chile, and Uruguay. What is evident from this table is that antibiotic therapy was administered irrespective of the level of service provided, while the use of other concomitant drugs (e.g., paracetamol, decadron, dexamethasone, ranitidine, acyclovir) and hydration and electrolyte therapies was dependent on the type of service provided. Laboratory examinations were performed more frequently in children who received care in the intensive care unit and intermediate neonatal units and in pediatric or infectious disease wards. In contrast, radiology tests were performed regardless of where the child received care. Moreover, children in Chile were routinely given followup visits after discharge, regardless of the level of care they received when they were hospitalized.

Across countries, $36 \%$ and $31 \%$ of the cost was attributed to intensive care and intermediate (neonatal) care, respectively. Emergency care attributed only $4 \%$ of the total treatment cost of pneumococcal disease. The cost of intensive care and intermediate care was higher in Chile, representing 40\% of the overall cost of treatment. In contrast, the cost of ambulatory care was higher in Uruguay, accounting for $66 \%$ of the overall cost of treatment. In Brazil, only three levels of care were reported for pneumococcal disease: ambulatory care, regular hospital care (in infectious disease ward), and intensive care. The latter contributed $11 \%$ to the overall cost of treatment in Brazil.

\section{Multiple linear regression analyses}

The regression analyses revealed the relative importance of the determinants (independent variables) in pre- dicting costs. Table 5 shows the results of the regression analysis models after controlling for skewness. For AOM due to any cause, the variable highlevel care $\left(x_{5}\right)$ was the only coefficient that was predictive of cost variations, with $t$ ratio 4.79 , which was statistically significant at the 5\% level. For pneumococcal meningitis, all except the variable for age $\left(x_{1}\right)$ were predictive of cost variations, as evident by $t$ ratios $-3.80\left(x_{2}\right),-3.32\left(x_{3}\right), 2.60\left(x_{4}\right)$, and $3.57\left(x_{5}\right)$, which were statistically significant at the 5\% level. For pneumonia due to any cause, the following coefficients were predictive of cost variations at the $5 \%$ level: Brazil $\left(x_{2}\right)$ Uruguay $\left(x_{3}\right)$, and high-level care $\left(x_{5}\right)$. For pneumococcal pneumonia, all coefficients except gender $\left(x_{4}\right)$ were statistically significant at the 5\% level.

To ensure that the equation satisfied the assumptions of normality and con- 
TABLE 5. Results of the regression analyses to determine the source of variations on health care costs for pneumococcal disease by age, gender, and level of care after controlling for the skewed distribution, Brazil, Chile, and Uruguay

\begin{tabular}{lcc}
\hline \multicolumn{1}{c}{ Variable } & Coefficient $^{\mathrm{a}}$ & $P$-value \\
\hline Pneumococcal meningitis & & \\
Age & Positive & 0.830 \\
Brazil & Negative & 0.001 \\
Uruguay & Positive & 0.002 \\
Gender & Positive & 0.005 \\
Level of care & Positive & 0.007 \\
Pneumococcal pneumonia & & \\
Age & Negative & 0.001 \\
Brazil & Negative & 0.009 \\
Uruguay & Negative & 0.002 \\
Gender & Negative & 0.377 \\
Level of care & Positive & 0.000 \\
Pneumonia & & \\
Age & Positive & 0.283 \\
Brazil & Negative & 0.003 \\
Uruguay & Negative & 0.001 \\
Gender & Negative & 0.388 \\
Level of care & Positive & 0.000 \\
Acute otitis mediab & & \\
Age & Positive & 0.394 \\
Brazil & Positive & 0.010 \\
Uruguay & Positive & 0.971 \\
Gender & Negative & 0.700 \\
Level of care & Positive & 0.002 \\
\hline a The coefficient is the mathematical weighting of the ex- \\
planatory variables in the equation. Positive coefficient is \\
the number greater than zero; & negative coefficient is the \\
number less than zero. & & \\
b Due to any cause. & & \\
& &
\end{tabular}

stant variance (no heteroscedasticity), the residuals of the coefficients were plotted in scatter graphs (not shown here). The graphs showed the presence of extreme values (cost outliers) in each of the models. Outliers added variability and uncertainty to the overall results of the regression models. To determine the effects of outliers on the relationship derived from the regression line, outliers were included in the primary regression analysis and excluded in the secondary regression analysis (Table 6). Exclusion of the outliers did not change the predictability of cost variations for the pneumococcal meningitis model (model 1), clinical pneumonia due to any cause model (model 3), and AOM due to any cause model (model 4). However, it reduced the predictability of cost variations for the pneumococcal pneumo-
TABLE 6. Results of the regression analyses to determine the source of variations on health care costs for pneumococcal disease by age, gender, and level of care with and without the outliers, Brazil, Chile, and Uruguaya

\begin{tabular}{lcccr}
\hline \multicolumn{1}{c}{ Variable } & $\begin{array}{c}\text { Pneumococcal } \\
\text { meningitis } \\
(t \text { ratio })\end{array}$ & $\begin{array}{c}\text { Pneumococcal } \\
\text { pneumonia } \\
(t \text { ratio })\end{array}$ & $\begin{array}{c}\text { Pneumonia } \\
(t \text { ratio })\end{array}$ & $\begin{array}{c}\text { AOM }^{b} \\
(t \text { ratio })\end{array}$ \\
\hline Including outliers & & & & \\
$\quad$ Age & 0.31 & -2.07 & -1.11 & 0.57 \\
Brazil & -3.80 & -6.69 & -4.41 & -1.08 \\
Uruguay & -3.32 & -2.10 & -14.81 & -1.90 \\
$\quad$ Gender & 2.60 & 0.001 & -1.35 & 1.08 \\
$\quad$ Level of care & 3.57 & 7.60 & 10.65 & 4.79 \\
Excluding outliers & & & -1.11 & 0.68 \\
Age & 0.05 & -1.69 & -4.38 & 1.24 \\
Brazil & -3.06 & -6.91 & -18.20 & -1.93 \\
Uruguay & -2.66 & -2.61 & -1.35 & 0.30 \\
$\quad$ Gender & 2.89 & 0.05 & 4.53 & 4.28 \\
Level of care & 5.32 & 6.13 & & \\
\hline a Outliers or outlying values are generated during a simulation on the extreme end of a distribution and are excluded from the \\
display range.
\end{tabular}

nia model (model 2), in terms of age. By excluding the outliers in this model, the variable age $\left(x_{1}\right)$ was no longer statistically significant at the $5 \%$ level, as was evident by the $t$ ratio -1.69 .

The normality of the residuals was tested using the skewness-kurtosis test. For model 4 (AOM due to any cause model), the equation passed the test at the 5\% level, with a $P$ (chisquare) of 0.35 . Similarly, the equation for model 2 (pneumococcal pneumonia model) passed the test of normality at the $5 \%$ level, with a $P$ (chi-square) of 0.31 . For models 1 (pneumococcal meningitis model) and 3 (pneumonia due to any cause model), the equations failed (rejected the null hypothesis of normality) the skewness-kurtosis test at the 5\% level, with $P$ (chi-square) less than 0.05 .

When heteroscedasticity (i.e., nonconstant variances) was tested, the equations for models 1, 3, and 4 failed the non-constant variance test at the 5\% level because their $P$ (chi-square) was less than 0.05 . The only model that passed the test of heteroscedasticity at the 5\% level was model 2 (pneumococcal pneumonia model).

Models 1, 3, and 4 failed the normality test and/or the heteroscedasticity test. This called into question the relia- bility of the estimates of the standard errors (and therefore the $t$ ratios) of the estimated regression coefficients for these three models. Based on this observation, it was not possible to rely on the $t$ ratios of models 1,3 , and 4 to determine which coefficients were significant and which were not significant. In contrast, model 2 (pneumococcal pneumonia) passed the normality test and the heteroscedasticity test. A significant proportion of the costs associated with pneumococcal pneumonia were likely to be explained by its relationship with the level of service provided and the country in which costs were incurred. Conversely, results of the regression analysis showed that the tendency of costs to change with variables (country, age, gender, and level of care) was not statistically significant for models 1,3 , and 4 .

\section{DISCUSSION}

\section{Main findings}

This study demonstrated that the cost of treating pneumococcal illnesses was considerable in the Latin American countries studied. Across countries, pneumococcal meningitis cost more to treat than pneumococcal 
pneumonia. This was indicative of disease severity. The size of the burden of pneumococcal meningitis in Chile, for example, was small but its costs were so pervasive that they outweighed the treatment costs of other pneumococcal illnesses. On the basis of this, researchers should target their efforts on costing diseases in countries that have differential burdens of pneumococcal disease. Better economic data should be obtained in countries where illnesses such as pneumococcal meningitis are a major health problem and are consistently more expensive.

Cases requiring hospital treatment were much more costly than those not requiring hospitalization. Therefore a major cost driver was hospital care, responding to severity, country, and inefficient levels of care. Age had a considerable effect on the cost of hospital care. Patients in the younger age group tended to incur higher costs of treatment due to extended length of stay in the hospital resulting from more severe or disabling conditions. In view of this evidence, researchers should focus data collection for future costing work on hospital inputs and costs, especially in the younger age population.

As expected, the greatest economic burden (health care costs) was in the upper-middle income country (Chile), with a 2005 gross national income (GNI) per capita of US\$ 3821 or more. This greater economic burden was due to higher treatment costs per child. The patterns of cost varied widely in certain population groups. An example of cost variation was found for the estimates of antibiotic therapy. This was the result of different treatments being administered (particularly at the beginning) and a wider variation of treatment dose range and costs for the period of the infection. Also apparent was the level of variation for the estimates of hospitalization, reflecting on the differences in length of stay. Hospital costs tended to peak early after admission and slowly decreased as treatment (mainly antibiotics) reduced the length of stay.

For economic evaluations, the most important consideration is that the rel- ative costs of the different items are consistent within each country column. For example, one would expect that the cost of a day in intensive care would be more costly than in an intermediate care unit and that the latter would be more costly than a day in a pediatric or infectious disease ward. This relationship held in all countries. Similarly, radiology tests were always more expensive than laboratory tests. Of the drug costs, antibiotic therapy was always more costly than electrolyte and hydration therapies.

Comparison of costs between countries was of less interest here as the concern was with country-specific evaluations. However, because the costs are applied to a set of resourceuse data derived from various centers in three countries, consistency of definition of items being costed was necessary. Overall, levels of health care expenditure and absolute price levels for health care resources varied between the three Latin American countries. Generally, one would expect the unit costs for all items to show the same relationship between two countries, for example, Chilean unit costs would be expected to be higher than those in Uruguay. From this study, it can be seen that this was the case except for certain procedures and follow-up care. In these cases the differences could arise from genuine differences in the relative costs for these items, from differences in financial responsibilities between health and non-health agencies, or from different definitions of the item or service being used. Where such differences appeared they were checked to ensure that there were genuine relative cost differences rather than inconsistencies in the cost measurement.

Detailed and complete sets of health care cost data were not readily available for most health care systems. In publicly funded systems direct patient billing only occurred for a limited number of items. In social insurance systems there was more direct charging, but the charge rates were often centrally determined and did not necessarily reflect true costs. The most comprehensive data usually related to charges or reimbursement rates rather than social opportunity costs. The latter tended to be available on a sitespecific basis leading to a conflict between precision and representativeness. On the basis of this evidence, researchers should consider the context in which decisions will be made before undertaking a study of this nature.

Although the procedures and items of health care resource use were defined a priori, variability of data availability between countries led to differences in the costing methods used. In some cases costs could not be obtained, for example, because procedures like cochlear implantation were not frequently reported in Chile. Moreover, diagnosis of pneumococcal disease is often difficult, especially in health care settings where blood cultures are not collected. Based on this, researchers should have a standardized methodology to ensure that the scope of the data is the same across countries.

Many factors caused cost variations. The findings of the multiple linear regression analysis highlighted some of the key sources for cost variations for pneumococcal pneumonia: levels of services provided (hospital versus ambulatory health centers) and country in which costs were incurred. However, the relationship of these variables with other diseases (pneumococcal meningitis, pneumonia due to any cause, AOM due to any cause) could not be explained, as the tendency of costs to change with these variables was not statistically significant at the $5 \%$ level for other pneumococcal disease models.

\section{Study limitations}

A few limitations need to be borne in mind. The first limitation stems from the fact that costs of follow-up care for patients with sequelae were difficult to estimate, as quality data sources related to the cost of sequelae were scarce. For this reason, only costs of treating the acute phase of the illness were considered.

On the question of potential doublecounting of medical staff costs in pro- 
cedures and per diems there was a variable experience between countries. It was not considered a problem for costs in intensive care as the staff there was separate from the staff providing general ward care. For neonatal care there was a possibility of some overlap but generally the medical staff in neonatal care were not directly involved in general ward care. The main area of difficulty remained the cost for general ward care. It was recognized that in all countries general ward per diem included some time spent on medical procedures.

The disparate nature of health care systems in these countries, in terms of organization and delivery of care and reimbursement of health care providers, led to a variable quantity and quality of readily available data on the costs of care across countries. In many cases it was necessary to depart from the intended approach because of this.

\section{Study implications}

The work undertaken here shows that cost estimation for pneumococcal disease treatment can be achieved and can provide "building blocks" to infer the costs and variability of costs in dif- ferent settings. This should encourage both central and local decision-makers to request cost data on a regular basis. The cost of pneumococcal disease can vary widely and some of this variation is associated with service characteristics. This finding can help inform health care administrators and providers as they plan new vaccine programs and develop contracting and pricing strategies. On this note, decisions on introducing a new vaccination program should be based on country-specific data, regardless of how similar countries might seem in terms of regional proximity and income levels. The focus of data collection for future costing studies should also be on diseases that are consistently most costly, as is the case for pneumococcal meningitis. It should not be inferred from this that patients with more frequently occurring but less pervasive infections (AOM due to any cause) should be ignored. Similarly, future research should consider focusing more on significant cost drivers, such as hospital care. These findings need to be balanced against the provision of good-quality care.

Acknowledgements. This work was funded by the Bill \& Melinda Gates
Foundation with the support of the Pan American Health Organization (PAHO), but full independence of methods and control over publication remain with the author along with responsibility for any errors. The author acknowledges and thanks the following investigators for their expert advice and for their tireless effort in the collection of health resources information: Dr. Ana Lúcia Andrade and Dr. Simonne Silva of the Universidade Federal de Goiás, Goiâna, Brazil; Dr. Rosario Palacio and Dr. Maria Hortal of the Centro Hospitalario Pereira Rossell, Montevideo, Uruguay; Dr. Rosanna Lagos of the Center for Vaccine Development in Chile; and Ms. Leonor Astroza of the Ministry of Health, Santiago, Chile. Also recognized is the generous assistance of the medical staff, nurses, epidemiologists, and parents who provided information through interviews and medical records. The author would also like to acknowledge and thank Professor Charles Normand of the University of Dublin for his critical review of the current work, and Dr. José Luis Di Fabio of the Pan American Health Organization for his support of the application to the Bill \& Melinda Gates Foundation.

\section{REFERENCES}

1. Mulholland K. Serious infections in young infants in developing countries. Vaccine. 1998;16:1360-2.

2. World Health Organization. 2004 Global Immunization Data. Available from http/www. who.int/immunization_monitoring/data/ GlobalImmunizationData.pdf. Accessed 14 August 2007.

3. Alsarraff R, Jung CJ, Perkins J, Crowley C, Alsarraff NW, Gates GA. Measuring the indirect and direct costs of acute otitis media. Arch Otolaryngol Head Neck Surg. 1999;125(1): $12-8$.

4. Kaplan B, Wandstrat TL, Cunningham JR. Overall cost in the treatment of otitis media. Pediatr Infect Dis J. 1997; 16(2 Suppl):S9-11.

5. Niemela M, Uhari M, Pokka T. Costs arising from otitis media. Acta Paediatr. 1999;88(5): 553-6.

6. Stool SE, Field MJ. The impact of otitis media. Pediatr Infect Dis J. 1989;8(1 Suppl):S11-4.
7. Arredondo A, Lockett LY, de Icaza E. Cost of diseases in Brazil: breast cancer, enteritis, cardiac valve disease and bronchopneumonia. Rev Saude Pub. 1995;29(5):349-54

8. Arredondo A, Damián T, de Icaza E. Una aproximación al estudio de costos de servicios de salud en México. Salud Publica Mex. 1995;37:437-45.

9. Guest JF, Morris A. Community-acquired pneumonia: the annual cost to the National Health Service in the UK. Eur Respir J. 1997;10(7):1530-4.

10. Lave JR, Lin CJ, Fine MJ, Hughes-Cromwick P. The cost of treating patients with communityacquired pneumonia. Semin Respir and Crit Care Med. 1999;20(3):189-97.

11. Ray NF, Baraniuk JN, Thamer M, Rinehart CS, Gergen PJ, Kaliner M, Josephs S, Pung YH. Healthcare expenditures for sinusitis in 1996: contributions of asthma, rhinitis, and other airway disorders. J Al- lergy and Clin Immunol. 1999;103(3 Pt 1): 408-14.

12. Concha-Barrientos M, Rodriguez Neira ICL, Aguilera-Sanhueza X, González Wiedmaier C. Estudio de costo efectividad: informe final. Santiago: Ministerio de Salud de Chile (MINSAL); 1998.

13. Constenla D, Palacio R. Estimación del costo promedio de potenciales componentes de neumococcias en Uruguay. In: Hortal $\mathrm{M}$, Iraola I, Camou T, eds. Avances multidisciplinarios para el control integral de Streptococcus pneumoniae; Uruguay-diez años de experiencia. Montevideo: Organización Panamericana de la Salud; 2004; pp. 137-44.

14. Constenla D, Gomez E, de la Hoz F, O'Loughlin R, Sinha A, Valencia JE, et al. The burden of pneumococcal disease and the cost effectiveness of a pneumococcal vaccine in Latin America and the Caribbean: a review of the evidence and a preliminary economic analy- 
sis. Washington, D.C.: Albert B. Sabin Vaccine Institute; 2007.

15. Valenzuela MT, O'Loughlin R, de la Hoz FP, Gomez E, Constenla D, Sinha A, et al. for the Technical Advisory Group. The burden of pneumococcal disease in Latin America and the Caribbean: A review of the evidence. The Lancet. Forthcoming 2008.

16. Constenla D. Evaluating the cost-effectiveness of a pneumococcal conjugate vaccination programme in Latin America [PhD thesis]. Lon- don: London School of Hygiene and Tropical Medicine. 2005. Pp. 153-228.

17. World Bank. World Development Indicators Online. Available from: http://www.world bank.org/data/wdi2004/index.htm. Accessed 23 January 2005.

18. American Medical Association. International Classification of Diseases; 10th Revision Clinical Modification (ICD-10-CM). Available from: http://www.who.int/classifications/ apps/icd/icd10online. Accessed 15 May 2006.
19. Cook R, Weisberg S. Residuals and influence in regression. New York: Chapman and Hall; 1982

Manuscript received 14 August 2006. Revised version accepted for publication 12 September 2007.

RESUMEN Objetivos. Estimar los costos de la enfermedad neumocócica en Brasil, Chile y Uruguay, describir cómo varían estos costos entre diferentes grupos de pacientes y discutir los factores que influyen en las variaciones de estos costos.

\section{Evaluación de los costos de la enfermedad neumocócica en países seleccionados de América Latina}

Métodos. El costo de la enfermedad neumocócica se estimó desde la perspectiva de la atención sanitaria. Inicialmente se establecieron estimados de referencia de los costos para cada país a partir de la información de los recursos sanitarios empleados, según los datos de cada paciente y los costos específicos de cada institución. Se construyeron modelos de regresión por separado para cuatro tipos de enfermedad neumocócica. Se realizaron las pruebas de asimetría-curtosis y de Cook-Weisberg para comprobar la normalidad de los residuos y la heterocedasticidad, respectivamente.

Resultados. El costo del tratamiento de la meningitis neumocócica fue de US\$ 5435 por cada niño, mientras el de la neumonía neumocócica fue menor, entre US\$372 y US\$ 3483 por niño. El costo del tratamiento de la otitis media aguda fue de US\$ 20 a US\$ 217 por niño. La principal fuente de variación en los costos de tratamiento fue el nivel de servicio brindado y el país en que se generaron los costos. No obstante, la tendencia de los costos a variar no fue estadísticamente significativa $(P>0,05)$ en la mayoría de los modelos de la enfermedad neumocócica.

Conclusiones. La enfermedad neumocócica constituye una notable carga económica para los sistemas de salud seleccionados de América Latina. Los patrones del costo de tratamiento de la enfermedad neumocócica mostraron una gran variación.

Palabras clave Costos y análisis de costos, costo de enfermedad, otitis media, neumonía, neumonía neumocócica, Streptococcus pneumonia, América Latina. 